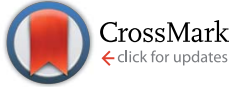

Cite this: RSC Adv., 2017, 7, 4806

Received 23rd October 2016 Accepted 2nd January 2017

DOI: 10.1039/c6ra25704f

www.rsc.org/advances

\section{Proposition and computational analysis of a kesterite/kesterite tandem solar cell with enhanced efficiency}

\author{
Uday Saha and Md. Kawsar Alam*
}

We propose a dual junction $\mathrm{Cu}_{2} \mathrm{ZnSnS}_{4} / \mathrm{Cu}_{2} \mathrm{ZnSnSe}{ }_{4}$ (kesterite/kesterite) based tandem configuration and analyze its prospect and viability as a solar cell. $\mathrm{Cu}_{2} \mathrm{ZnSnS}_{4}$ and $\mathrm{Cu}_{2} \mathrm{ZnSnSe}_{4}$, both having the kesterite crystal structure, are used as the main absorbers for the top and bottom of cells, respectively. We optimize the thickness of the absorbers using optoelectronic simulations and investigate the effect of absorber thickness on short circuit current density and open circuit voltage. The optimized thicknesses for peak efficiency are found to be $200 \mathrm{~nm}$ and $850 \mathrm{~nm}$ for $\mathrm{Cu}_{2} \mathrm{ZnSnS}_{4}$ and $\mathrm{Cu}_{2} \mathrm{ZnSnSe}_{4}$, respectively. The maximum efficiency of the tandem cell is estimated to be $19.87 \%$ including recombination effects such as Shockley-Read-Hall $(\mathrm{SRH})$ and radiative recombination mechanisms. We also investigate the effect of band gap on the performance of the tandem cell and show that a $21.74 \%$ efficient tandem cell can be achieved for optimized band gaps. Finally, we report that efficiency could be further enhanced by replacing the CaS buffer layer with eco-friendly ZnS buffer layer and optimizing the tandem structure. The proposition and computational analysis presented in this work may help in achieving higher efficiency kesterite solar cells.

\section{Introduction}

In order to avoid negative irreversible effects of traditional energy resources (such as fossil fuels or nuclear power plants etc.), energy harvesting through solar photovoltaics is on the leading edge among other renewable energy resources. Although silicon based solar cells currently share about $85 \%$ of the total photovoltaic market, ${ }^{1}$ chalcogenide-based thin film solar cells (such as CIGS, CdTe, CZTS etc.) are being explored extensively among other promising structures and may form the foundation of next generation photovoltaics technology because of their high power conversion efficiency (PCE), low material usage, direct and tunable band gap and low deposition cost on a large area. ${ }^{1-5}$ Despite the fact that $\mathrm{CuIn}_{1-x} \mathrm{Ga}_{x} \mathrm{Se}_{2}$ (CIGS) based solar cells hold the world record efficiency value $(21.7 \%)^{6}$ among all thin film technologies, the usage of earth rarer costly metals (e.g. indium (In), gallium (Ga)) makes their production limited. Kesterite photovoltaics, utilizing $\mathrm{Cu}_{2} \mathrm{ZnSnS}_{4}$ (CZTS), $\mathrm{Cu}_{2} \mathrm{ZnSnSe}_{4}$ (CZTSe) and $\mathrm{Cu}_{2} \mathrm{ZnSn}\left(\mathrm{S}_{1-x} \mathrm{Se}_{x}\right)_{4}$ (CZTSSe) absorbers, are emerging as one of the most promising replacement for the chalcopyrite solar cells through the substitution of the rarer metals In and Ga of the CIGS absorber with comparatively earth-abundant and lower cost zinc $(\mathrm{Zn})$ and tin $(\mathrm{Sn}){ }^{6-9}$ In addition, kesterite absorbers exhibit high absorption coefficient $\left(>10^{4} \mathrm{~cm}^{-1}\right)$ and direct tunable band gap in the range of 1.0-1.56 eV which allow effective absorption

Department of Electrical and Electronic Engineering, Bangladesh University of Engineering and Technology, Dhaka 1205, Bangladesh.E-mail: kawsaralam@eee. buet.ac.bd; kawsar@ece.ubc.ca; Tel: +880 1712526059 of incident photons in few microns' thickness of absorbers. ${ }^{10-12}$ Moreover, their properties are closely related to CIGS absorbers because of the similarity in crystal structure and isovalency. ${ }^{1,7,13-15}$ All these facts make kesterite an interesting field of research. However, kesterite solar cell currently suffers from open circuit voltage deficit and poor efficiency. The highest efficiency reported by single junction kesterite solar cell is $12.6 \%$ employing CZTSSe absorber with an open circuit of $510 \mathrm{mV} .^{6,11}$ The limiting factors behind poor performance are bulk defects, secondary phase formation, grain boundaries, kesterite/buffer layer and kesterite/back contact interfaces. ${ }^{10,12,16}$ Therefore, in order to compete with existing solar cell technologies, significant research and effort are needed.

Recently, Hsieh et al. reported efficiency enhancement through K-doping and optimization of n-type window layer. ${ }^{17}$ However, rear surface recombination and poor minority carrier life time in kesterite absorbers significantly reduce the fill factor of their reported cell. Another attempt was made by Neuschitzer et al. by manipulating grain growth with Ge doping. ${ }^{18}$ However, shallow defects were identified in the cell for optimal and high Ge doping which act as electron-hole recombination centers and limit the photovoltaic efficiency significantly. Kim et al. enhanced carrier life time by controlling the thickness of ZnS precursor layer which increased the PCE of single junction kesterite solar cell up to $9.1 \%$ with CZTSSe absorber. ${ }^{19}$ It was also reported that the performance can be further improved with $\mathrm{Al}_{2} \mathrm{O}_{3}$ rear surface passivation layer with nanosized point openings by reducing rear surface recombination and the impact of secondary phase segregation. ${ }^{20}$ Further, interfacial microstructure and chemistry 
of CdS/CZTS heterojunction were studied by Liu et al. ${ }^{21}$ They improved the minority carrier life time by eliminating interfacial defects with chemical bath deposition (CBD) process. However, the disposal and waste recycling process in CBD could be a matter of concern for industry. ${ }^{22}$ Different types of hybrid buffer layer were also used to increase open circuit voltage and efficiency of kesterite solar cell. ${ }^{23,24}$ Although noteworthy increases in PCE of kesterite solar cell have been achieved in recent years, further improvements are still required to enhance efficiency up to the level of CIGS solar cells and to increase the commercial viability of these types of photovoltaics.

In order to increase the open circuit voltage and enhance the efficiency, tandem junction topology is an established technique. Recently, Todorov et al. reported perovskite/CZTSSe solar cell with an efficiency of $16 \%{ }^{25}$ The performance of their perovskite/ CZTSSe cell is limited by high resistance and low optical transmission of aluminum (Al) layer. The cell suffers from stability issues due to perovskite ${ }^{26}$ and increased fabrication cost due to high annealing temperature. ${ }^{27}$ Moreover, other disadvantages of perovskites such as limited device life time, poor crystallinity, degradation under environmental influence, ${ }^{28}$ use of toxic metal (lead), ${ }^{29}$ uncontrollable surface morphology ${ }^{30}$ etc., the use of perovskite/CZTSSe need more organized research on perovskites. Although, kesterite absorbers are suitable for both upper and lower cells in multi-junction solar cells due to their tunable band gap property, no kesterite/kesterite tandem cell has yet been reported in literature. Such tandem junction solar cell would be eco-friendly having low fabrication cost as well as printable with existing technologies. ${ }^{31-34}$ Moreover, this may overcome the limitations of perovskite/CZTSSe cell with the use of CZTS in place of perovskite. In this work, we investigate the prospect of kesterite/kesterite dual-junction tandem solar cells by computational analysis where CZTS (band gap $\sim 1.56 \mathrm{eV})^{35}$ and CZTSe (band gap $\sim 1.04 \mathrm{eV})^{36}$ are used as absorber layers for top and bottom cells, respectively. We optimize the structure to achieve maximum efficiency out of these structures. We also analyze the effect of top and bottom cells' band gap and composition of buffer layer on the efficiency of our proposed tandem cell.

\section{Simulation methodology}

Fig. 1 represents the structure of a CZTS/CZTSe tandem junction solar cell. CZTS and CZTSe are the main absorbing materials of top and bottom cells, respectively. We have designed the top cell architecture according to the experimental structure reported by Shin et al. ${ }^{37}$ The cell layers are $\mathrm{AZO} / \mathrm{ZnO} / \mathrm{CdS} / \mathrm{CZTS}$. Here, CdS is utilized as a buffer layer and n-doped transparent $\mathrm{ZnO}$ window layer works as the top surface field layer. Aluminum doped $\mathrm{ZnO}$ (AZO) is used to reduce the series resistance of the overall tandem cell. The thicknesses of AZO, ZnO and CdS in the top cell are $400 \mathrm{~nm}, 50 \mathrm{~nm}$ and $70 \mathrm{~nm}$, respectively. A $100 \mathrm{~nm}$ thick magnesium fluoride $\left(\mathrm{MgF}_{2}\right)$ is placed on top as an antireflection coating layer. On the other hand, we have followed the experimental design proposed by Wang et al. ${ }^{11}$ to model the bottom cell structure. The bottom cell consists of $\mathrm{ZnO} / \mathrm{CdS} / \mathrm{CZTSe}$. The roles of CdS and $\mathrm{ZnO}$ are similar to that of the top cell. The thicknesses of $\mathrm{ZnO}$, CdS and Mo in the bottom cell are $50 \mathrm{~nm}, 150 \mathrm{~nm}$ and

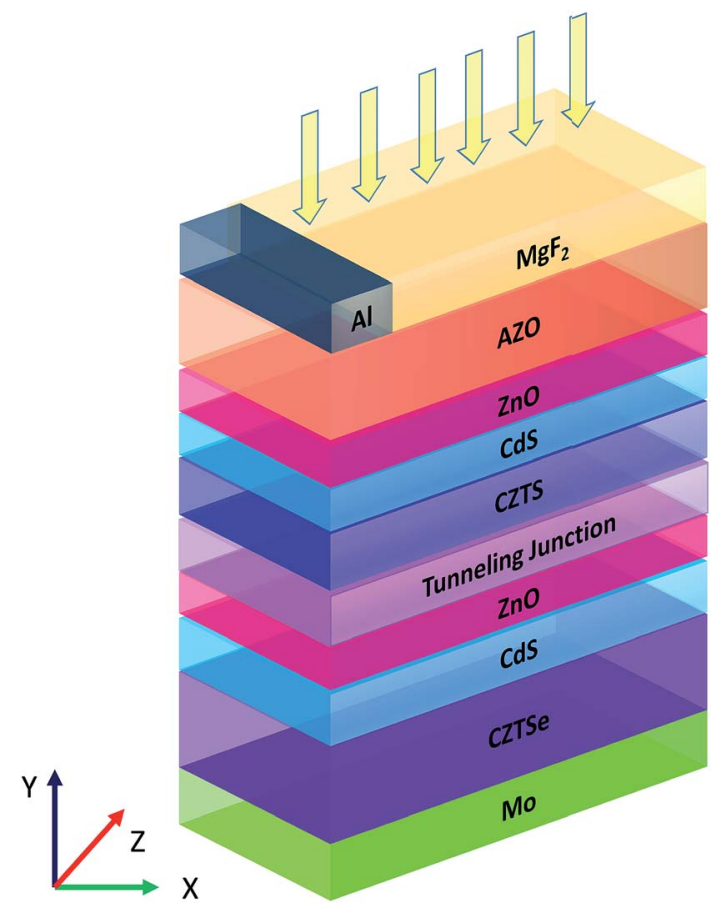

Fig. 1 The structure of $\mathrm{Cu}_{2} \mathrm{ZnSnS}_{4} / \mathrm{Cu}_{2} \mathrm{ZnSnSe}{ }_{4}$ tandem cell.

$500 \mathrm{~nm}$, respectively. As shown in Fig. 1. Molybdenum (Mo) is used as the back contact whereas $\mathrm{Al}$ contact with $10 \%$ coverage is used as the front electrode. A tunneling junction made of ITO is considered between the two cells. Such tunneling junction with ITO has been experimentally fabricated by Todorov et al. ${ }^{25} \mathrm{Also}$, CZTS/ITO and ITO/ZnO interfaces have been shown to be experimentally realizable. ${ }^{38-41}$ Therefore, the proposed tandem structure can be implemented with the existing fabrication technology.

Study of the structure shown in Fig. 1 was done in two parts: (a) calculation of absorption and carrier generation through optical simulation and (b) estimation of PCE from electrical simulation. In the optical part, we solved Maxwell's curl equations through finite difference time domain (FDTD) analysis to find out the optical electric field $\left(\overrightarrow{E_{\mathrm{op}}}\right)$ distribution inside different layers. Each material was modeled by its respective refractive index $(n)$ and extinction coefficient $(\kappa)$ as a function of wavelength. Then, the absorbed power $\left(P_{\text {abs }}\right)$ can be calculated from optical electric field distribution and imaginary part of complex dielectric constant as

$$
P_{\text {abs }}=-\frac{1}{2} \omega\left|\overrightarrow{E_{\mathrm{op}}}(\vec{r}, \omega)\right|^{2} \Im\{\varepsilon(\vec{r}, \omega)\},
$$

where $\omega$ is the angular frequency and $\varepsilon(\vec{r}, \omega)$ is the dielectric constant. The generation rate, $G(\vec{r})$ was calculated according to the following equations:

$$
\begin{gathered}
G(\vec{r})=\int g(\vec{r}, \omega) \mathrm{d} \omega, \\
g(\vec{r}, \omega)=\frac{P_{\mathrm{abs}}}{\hbar \omega}=-\frac{\pi}{h}\left|\overrightarrow{E_{\mathrm{op}}}(\vec{r}, \omega)\right|^{2} \mathfrak{\jmath}\{\varepsilon(\vec{r}, \omega)\},
\end{gathered}
$$


where $h$ is the Planck's constant. Periodic boundary condition was used in horizontal $(X)$ direction and perfectly matched layer (PML) boundary condition was applied for top and bottom faces (in $Y$-direction). AM 1.5G standard solar spectrum has been used as the input radiation source.

The electrical characteristics were calculated in two steps. In the first step, we simulated top and bottom cells separately and calculated their characteristics features. In this regard, we solved the Poisson's equation, drift-diffusion equations and continuity equations (eqn (4)-(8)) self consistently for electrons and holes and find the $J-V$ characteristics, open circuit voltage $\left(V_{\text {oc }}\right)$, short circuit current $\left(J_{\mathrm{sc}}\right)$, fill factor $(\mathrm{FF})$ and efficiency $(\eta)$ of top and bottom cells independently.

$$
\begin{gathered}
-\nabla \cdot\left(\varepsilon_{\mathrm{dc}} \nabla V\right)=q \rho, \\
\overrightarrow{J_{\mathrm{n}}}=q \mu_{\mathrm{n}} n \vec{E}+q D_{\mathrm{n}} \nabla n, \\
\overrightarrow{J_{\mathrm{p}}}=q \mu_{\mathrm{p}} p \vec{E}-q D_{\mathrm{p}} \nabla p, \\
\frac{\partial n}{\partial t}=\frac{1}{q} \nabla \cdot \overrightarrow{J_{\mathrm{n}}}-R_{\mathrm{n}},
\end{gathered}
$$

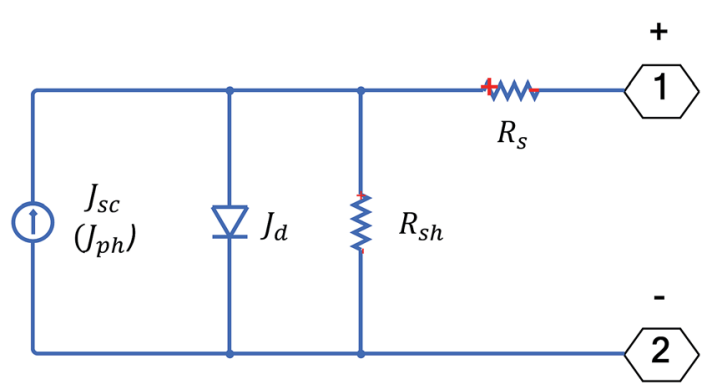

Fig. 2 Equivalent circuit for individual cells.

$$
\frac{\partial p}{\partial t}=-\frac{1}{q} \nabla \cdot \overrightarrow{J_{\mathrm{p}}}-R_{\mathrm{p}}
$$

where $\varepsilon_{\mathrm{dc}}$ is the dc dielectric permittivity, $V$ is the electrostatic potential (electric field, $\vec{E}=-\nabla V$ ), $\rho$ is the net charge density ( $\rho$ $=p-n+C$, which includes the contribution $C$ from the ionized impurity density), $\overrightarrow{J_{\mathrm{n}(\mathrm{p})}}$ is the electron (hole) current density, $q$ is the positive electron charge, $\mu_{\mathrm{n}(\mathrm{p})}$ is the mobility of electron (hole), $D_{\mathrm{n}(\mathrm{p})}$ is the diffusivity of electron (hole) $\left(D_{\mathrm{n}(\mathrm{p})}=\mu_{\mathrm{n}(\mathrm{p})} \frac{k_{\mathrm{B}} T}{q}\right), n$ and $p$ are electron and hole densities, respectively, $R_{\mathrm{n}(\mathrm{p})}$ is the net recombination rate (the difference between the recombination rate and generation rate), $k_{\mathrm{B}}$ is the Boltzmann constant and $T$ is the temperature (the subscripts $n$ and $\mathrm{p}$ indicate quantities that are specific to the carrier type). Generation rate calculated from the optical simulation was given as an input in the continuity equations and the equation set (eqn (4)-(8)) were solved self-consistently. In this way, we found the individual characteristics of top and bottom cells. We have used Lumerical FDTD and Device solvers for the optical and electrical simulations, respectively. The cells were modeled by the equivalent circuit shown in Fig. 2 . In the circuit, $J_{\mathrm{ph}}$ is the photon generated current density, $R_{\mathrm{S}}$ and $R_{\mathrm{sh}}$ represent series and shunt resistances, respectively. The current density through the diode, $J_{\mathrm{d}}$ can be calculated from:

$$
J_{\mathrm{d}}=J_{\mathrm{s}}\left(\mathrm{e}^{\frac{q V_{\mathrm{d}}}{n_{\mathrm{d}} k_{\mathrm{B}} T}}-1\right),
$$

where $J_{\mathrm{s}}$ is the dark diode reverse-saturation current, $V_{\mathrm{d}}$ is the bias voltage across the diode and $n_{\mathrm{d}}$ is the ideality factor.

Once we obtained the model parameters of each cell, we applied the series circuit rules on top and bottom cells' parameters via Matlab simulink and generated the $J-V$ characteristics of the tandem cell (Fig. 3). The tunneling junction was modeled as ohmic contact. One of the main advantages of using this approach is that a comparison can be conveniently made

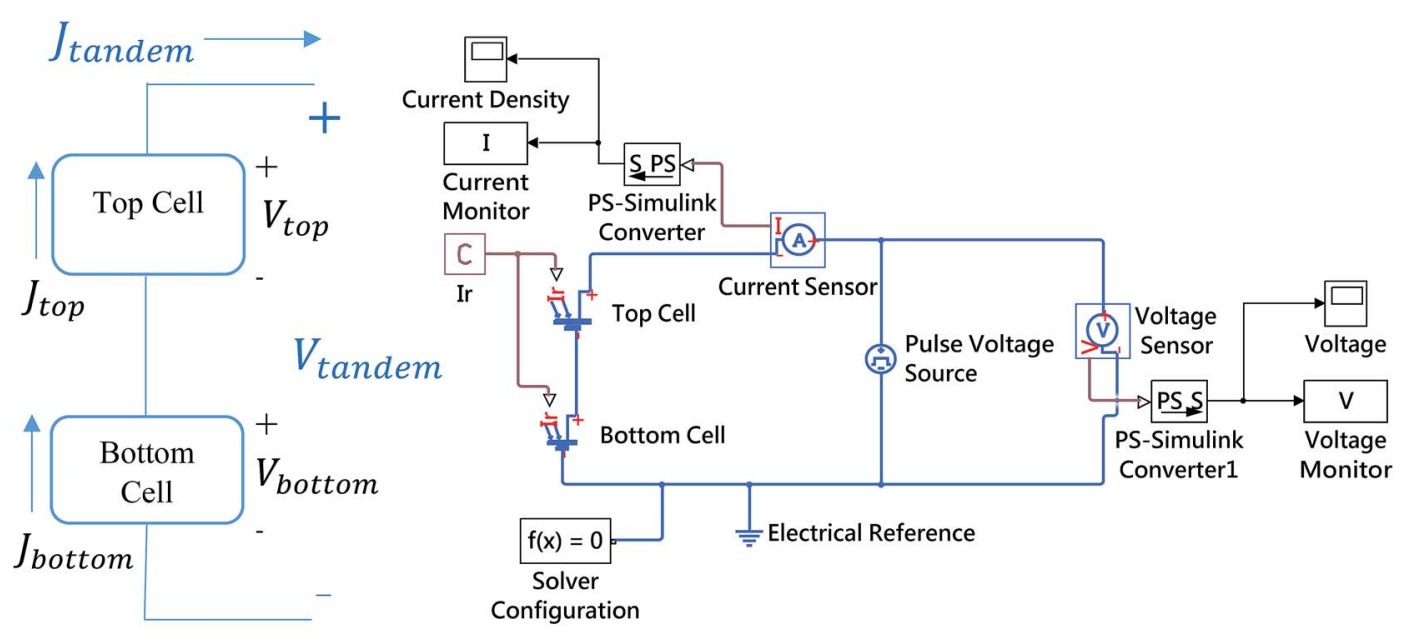

(a)

(b)

Fig. 3 (a) Topology of $\mathrm{Cu}_{2} \mathrm{ZnSnS}_{4} / \mathrm{Cu}_{2} \mathrm{ZnSnSe} e_{4}$ tandem stacks (b) circuit diagram of simulated overall tandem structure. 
with the performance of individual cells as well as their roles in the tandem configuration could be clearly comprehended. Using circuit model for computing tandem cell characteristics is also computationally efficient.

\section{Results and discussion}

At first, we benchmarked the $J-V$ characteristics derived from circuit model with the device simulation results for each cell. To match these characteristics, we first assumed that equivalent circuit only comprised of a photon generated current source $\left(J_{\mathrm{ph}}\right)$, a diode $\left(J_{\mathrm{d}}\right)$ and a shunt resistance $\left(R_{\mathrm{Sh}}\right)$. Then, we simulated the $J-V$ characteristics from device simulation without considering recombination and compared these characteristics with the circuit model. In the next step, we calculated $J-V$ characteristics from device simulation considering recombination parameters and matched the same with circuit model considering series resistance $\left(R_{\mathrm{S}}\right)$ in the model. In order to get the best possible match, we considered that ideality factor $\left(n_{\mathrm{d}}\right)$ is 1.01 and 1.015 for top and bottom cells, respectively. $J_{\mathrm{ph}}$ is assumed to be equal to $J_{\mathrm{sc}}$ and $J_{\mathrm{s}}$ is calculated from $V_{\mathrm{oc}}$. Series resistances for both top and bottom cells are low enough to validate the assumption $J_{\mathrm{ph}}=J_{\mathrm{sc}}$. The values of $R_{\mathrm{s}}$ and $R_{\mathrm{Sh}}$ are dynamically changed with absorber thickness to match the $J-V$ characteristics of device simulation. Typical matching of $J-V$ and $P-V$ characteristics for $230 \mathrm{~nm}$ CZTS and $850 \mathrm{~nm}$ CZTSe absorbers is shown for top and bottom cells in Fig. 4 and 5, respectively. Also, Table 1 shows a comparison of $V_{\mathrm{oc}}, J_{\mathrm{sc}}, \mathrm{FF}$ and $\eta$ of the circuit model with device simulations.

As can be seen from Table 1, circuit model is capable of reproducing the behavior of a cell under different conditions
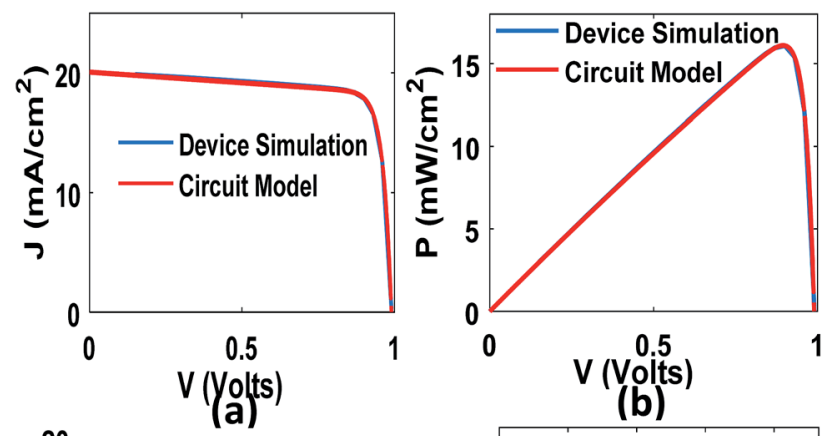

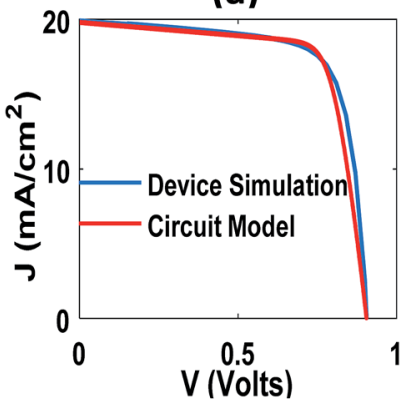

(c)

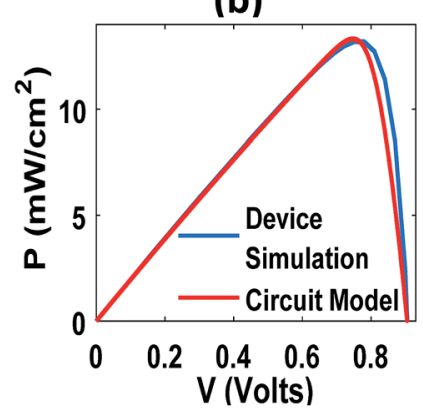

(d)
Fig. 4 Comparison between device simulation and circuit model for top cell (a) $J-V$ characteristic without recombination (b) $P-V$ characteristic without recombination, (c) $J-V$ characteristic with recombination and (d) $P-V$ characteristic with recombination.

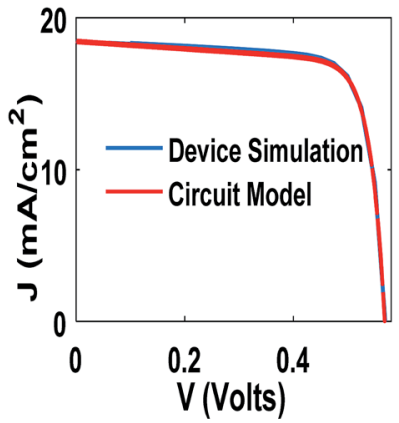

(a)
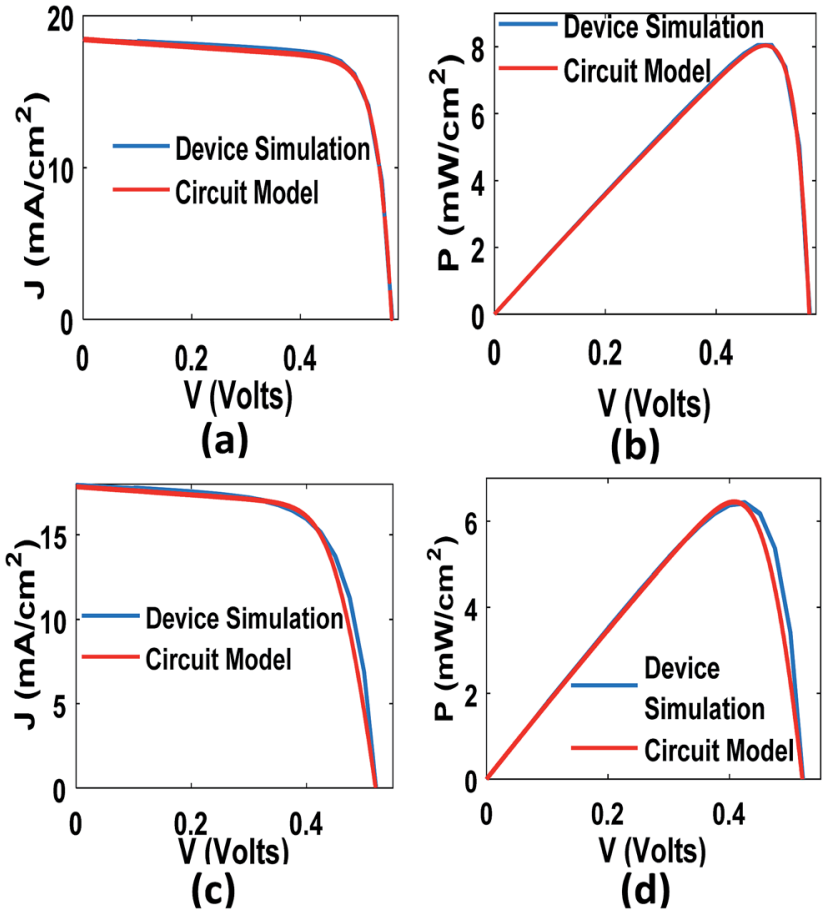

(b)

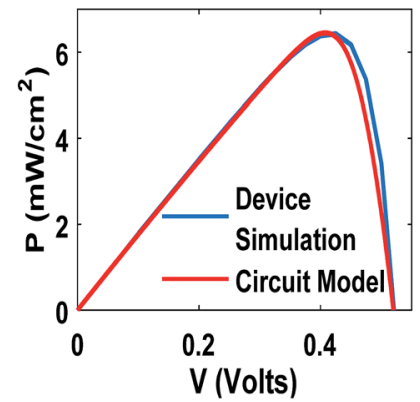

(d)

Fig. 5 Comparison between device simulation and circuit model for bottom cell (a) $J-V$ characteristic without recombination (b) $P-V$ characteristic without recombination, (c) $J-V$ characteristic with recombination and (d) $P-V$ characteristic with recombination.

(with or without considering recombination). Thus, we modeled the experimental structures to benchmark our used parameters. Table 2 shows the comparison of our model with experimentally reported values. In this regard, the optical and basic electrical parameters as well as recombination parameters were taken from literature (optical, ${ }^{15,42-50}$ electrical $^{\mathbf{1 5 , 3 6 , 5 1 - 6 1}}$ (listed in Table 3)). We considered SRH recombination mechanism for bulk defect and radiative recombination mechanisms for the direct band gap nature of the absorbers. We used much less carrier life time than that of the reported values in literature to predict the minimum performance limit of the proposed tandem structure.

Having been convinced by the accuracy of our methodology, we analyzed and optimized the performance of the proposed CZTS/CZTSe tandem cell. To start the calculation with reasonable values of absorber thicknesses, we first examined the variation of PCE of top and bottom cells separately as a function of absorber thickness (Fig. 6). As can be seen from the figure, efficiencies of the top and bottom cells are maximized at $\sim 800 \mathrm{~nm}$ and $\sim 1200 \mathrm{~nm}$ thicknesses of CZTS and CZTSe, respectively. Therefore, as a starting point of our analysis, we chose a $600 \mathrm{~nm}$ thick CZTS and $1200 \mathrm{~nm}$ thick CZTSe absorbers keeping in mind the advantages of using thin films (note that we have later varied both absorber thicknesses within a wider range to arrive at an optimum combination). This yields an $8.89 \%$ efficient tandem cell with $V_{\mathrm{oc}}=1.124 \mathrm{~V}, J_{\mathrm{sc}}=11.98 \mathrm{~mA}$ $\mathrm{cm}^{-2}$ and $\mathrm{FF}=0.679$. In this configuration, efficiencies of the top and bottom cells are calculated to be $14.57 \%$ and $2.82 \%$, respectively. Therefore, the tandem cell actually produces 
Table 1 Comparison of performance metrics between device simulation and circuit model

\begin{tabular}{|c|c|c|c|c|c|c|}
\hline & & & $V_{\mathrm{oc}}(\mathrm{V})$ & $J_{\mathrm{sc}}\left(\mathrm{mA} \mathrm{cm}{ }^{-2}\right)$ & FF & Efficiency (\%) \\
\hline \multirow[t]{4}{*}{ Without recombination } & \multirow[t]{2}{*}{ Top cell (CZTS) } & Device simulation & 0.990 & 20.06 & 0.810 & 16.09 \\
\hline & & Circuit model & 0.990 & 20.06 & 0.811 & 16.10 \\
\hline & \multirow[t]{2}{*}{ Bottom cell (CZTSe) } & Device simulation & 0.569 & 18.43 & 0.768 & 8.05 \\
\hline & & Circuit model & 0.568 & 18.43 & 0.767 & 8.04 \\
\hline \multirow[t]{4}{*}{ With recombination } & \multirow[t]{2}{*}{ Top cell (CZTS) } & Device simulation & 0.906 & 19.93 & 0.731 & 13.20 \\
\hline & & Circuit model & 0.905 & 19.79 & 0.744 & 13.32 \\
\hline & \multirow[t]{2}{*}{ Bottom cell (CZTSe) } & Device simulation & 0.521 & 17.96 & 0.687 & 6.43 \\
\hline & & Circuit model & 0.520 & 17.85 & 0.695 & 6.45 \\
\hline
\end{tabular}

Table 2 Comparison of simulation results with the experimental data of individual cells

\begin{tabular}{lllll}
\hline & $V_{\text {oc }}(\mathrm{V})$ & $J_{\text {sc }}\left(\mathrm{mA} \mathrm{cm}^{-2}\right)$ & FF & Efficiency (\%) \\
\hline $\begin{array}{l}\text { Top cell } \\
\text { Experimental }^{37}\end{array}$ & 0.661 & 19.50 & & \\
Simulation & 0.648 & 21.25 & 0.658 & 8.40 \\
& & & 0.621 & 8.54 \\
Bottom cell $_{\text {Experimental }}^{11}$ & 0.513 & 35.20 & & \\
Simulation & 0.533 & 33.91 & 0.698 & 12.60 \\
& & & 0.704 & 12.73
\end{tabular}

a lower efficiency than that of the top cell. The primary reason behind such poor performance of the tandem configuration can be attributed to the mismatch of current densities in top and bottom cells $\left(J_{\text {sc,top }}=23.24 \mathrm{~mA} \mathrm{~cm}{ }^{-2}, J_{\text {sc,bottom }}=11.05 \mathrm{~mA}\right.$ $\left.\mathrm{cm}^{-2}, V_{\mathrm{oc}, \text { top }}=0.693 \mathrm{~V}, V_{\mathrm{oc}, \text { bottom }}=0.451 \mathrm{~V}\right)$. Furthermore, the extra amount of current lost due to $J_{\mathrm{sc}}$ mismatching (as the tandem cell follows the cell with lower $J_{\text {sc }}$ ) may cause resistive heating which could further degrade the performance of tandem cell by lowering the band gap of the main absorbers. ${ }^{15}$ To avoid these unwanted effects and maximize the efficiency of tandem cell, current matching between top and bottom cells is the most crucial factor similar to any tandem configuration.

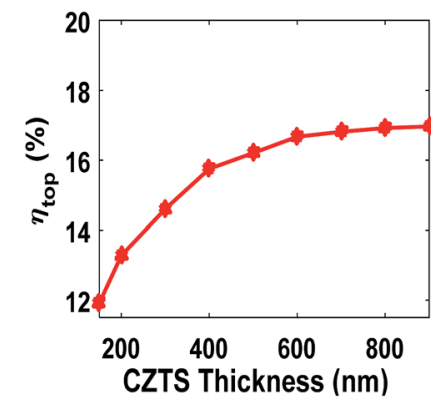

(a)

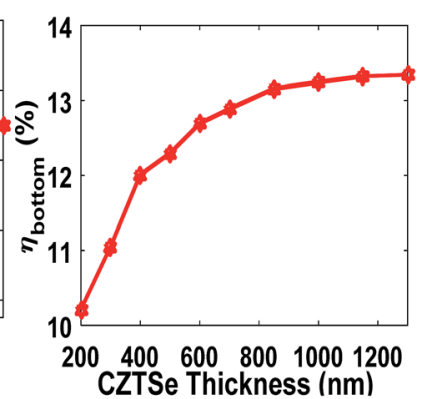

(b)
Fig. 6 Dependence of efficiencies of the top and bottom cells on the thickness of CZTS and CZTSe, respectively (a) top cell $\eta_{\text {top }}$ and (b) bottom cell $\eta_{\text {bottom }}$.

Therefore, we attempted to match the short current density in top and bottom cells by varying the thickness of main absorbers. The results are summarized in Fig. 7 .

Fig. 7(a) represents the dependence of tandem cell's $J_{\mathrm{sc}}$ on the thickness of CZTS and CZTSe absorbers. It is known that $J_{\mathrm{sc}}$ of the tandem cell is approximately equal to the minimum $J_{\mathrm{sc}}$ of top and bottom cells, and it maximizes when $J_{\mathrm{sc}}$ of top and bottom cells equals to each other. In tandem configuration, top and bottom cells absorb the shorter and longer wavelength

Table 3 Basic electrical parameters and recombination parameters used in simulations

\begin{tabular}{|c|c|c|c|c|c|c|}
\hline Features & $\operatorname{CZTS}(\mathrm{p})^{15,56,57}$ & CZTSe $(\mathrm{p})^{15,36,51}$ & $\mathrm{CdS}(\mathrm{n})^{58,59}$ & $\mathrm{ZnS}(\mathrm{n})^{52,55,58,59}$ & $\mathrm{ZnO}(\mathrm{n}+)^{53,54,58-60}$ & AZO $(\mathrm{n}++)^{58,59,61}$ \\
\hline DC permittivity & 7 & 7 & 10 & 9 & 9 & 9 \\
\hline Band gap (eV) & 1.56 & 1.04 & 2.42 & 3.58 & 3.37 & 3.37 \\
\hline Electron affinity (ev) & 4.1 & 4.05 & 3.75 & 3.8 & 4 & 4 \\
\hline Electron effective mass $\left(m_{\mathrm{e}} / m_{\mathrm{o}}\right)$ & 0.18 & 0.07 & 0.25 & 0.22 & 0.275 & 0.275 \\
\hline Hole effective mass $\left(m_{\mathrm{p}} / m_{\mathrm{o}}\right)$ & 2 & 0.2 & 5 & 1.76 & 0.59 & 0.59 \\
\hline Electron mobility $\left(\mathrm{cm}^{2} \mathrm{~V}^{-1} \mathrm{~s}^{-1}\right)$ & 100 & 145 & 160 & 230 & 150 & 50 \\
\hline Hole mobility $\left(\mathrm{cm}^{2} \mathrm{~V}^{-1} \mathrm{~s}^{-1}\right)$ & 25 & 35 & 15 & 40 & 50 & 5 \\
\hline Acceptor concentration $\left(\mathrm{cm}^{-3}\right)$ & $5 \times 10^{16}$ & $5 \times 10^{15}$ & 0 & 0 & 0 & 0 \\
\hline Donor concentration $\left(\mathrm{cm}^{-3}\right)$ & 0 & 0 & $\begin{array}{l}9 \times 10^{16} \\
\text { (top) } \\
5 \times 10^{16} \\
\text { (bottom) }\end{array}$ & $\begin{array}{l}9 \times 10^{16} \\
\text { (top) } \\
5 \times 10^{16} \\
\text { (bottom) }\end{array}$ & $1.5 \times 10^{17}$ & $8 \times 10^{18}$ \\
\hline SRH (life time in seconds) & $2.7 \times 10^{-10}$ & $1.5 \times 10^{-9}$ & $7.5 \times 10^{-10}$ & $5.5 \times 10^{-10}$ & - & - \\
\hline $\begin{array}{l}\text { Radiative recombination } \\
\text { (ehp capture rate } \mathrm{cm}^{3} \mathrm{~s}^{-1} \text { ) }\end{array}$ & $1.04 \times 10^{-10}$ & $1.04 \times 10^{-10}$ & $1.02 \times 10^{-10}$ & $1.5 \times 10^{-10}$ & - & - \\
\hline
\end{tabular}




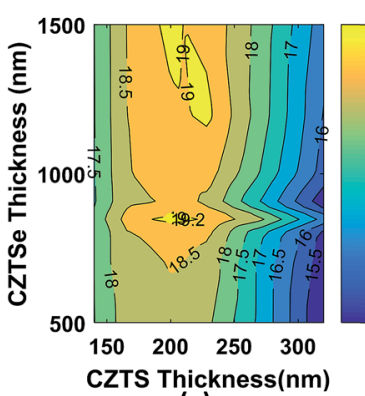

(a)

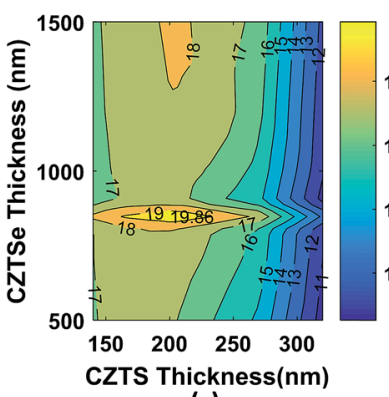

(c)

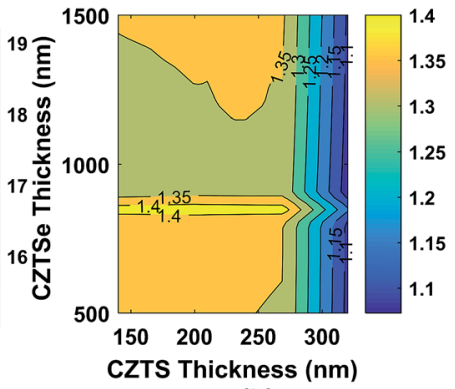

(b)

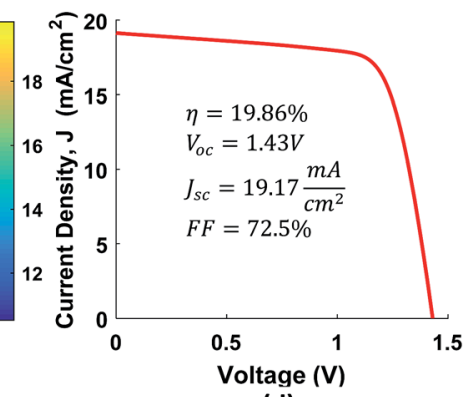

(d)

Fig. 7 Characteristics of tandem cell with the variation of the thickness of the main absorbers (a) short circuit current density $J_{\text {sc, }}$ (b) open circuit voltage, $V_{\text {oc }}$ (c) efficiency, $\eta_{\text {tandem }}$ and (d) $J-V$ characteristics of optimized tandem cell where the thickness of CZTS and CZTSe are $200 \mathrm{~nm}$ and $850 \mathrm{~nm}$, respectively.

photons of the solar spectrum, respectively. To match the $J_{\mathrm{sc}}$ of both cells, optical power absorption in two cells must be approximately equal. As the absorption depth of shorter wavelength photons is lower than that of longer wavelength photons, top cell absorbs a significant amount of radiation at a relatively lower thickness of the absorber ( $\sim 160$ to $240 \mathrm{~nm})$ which yielded a higher $J_{\mathrm{sc}}$ than that of the bottom cell as discussed above. To be equal with the top cell's $J_{\mathrm{sc}}$, thickness of bottom cell's absorber must be increased. Loops in the Fig. 7(a) indicate higher $J_{\mathrm{sc}}$ regions where top and bottom cell's $J_{\mathrm{sc}}$ matches approximately. A maximum $J_{\mathrm{sc}}$ of $19.17 \mathrm{~mA} \mathrm{~cm}^{-2}$ was calculated in the tandem cell with $\sim 200 \mathrm{~nm}$ CZTS and $\sim 850 \mathrm{~nm}$ CZTSe. If the thickness of CZTS absorber is increased beyond $240 \mathrm{~nm}$, it utilizes the solar spectrum in such a way that leaves small power behind for the bottom cell. In that case, $J_{\mathrm{sc}}$ of the bottom cell increases monotonically with the thickness of CZTSe absorber and fails to match with the $J_{\mathrm{sc}}$ of top cell. Since we observe high $J_{\text {sc }}$ of tandem cell at multiple combinations of absorbers thickness, it is necessary to analyze the effect absorbers thickness on tandem cell's open circuit voltage, $V_{\text {oc }}$.

We investigated the dependence of $V_{\text {oc }}$ on the absorber thicknesses and obtained a similar contour plot as shown in Fig. 7(b). The $V_{\mathrm{oc}}$ of tandem cell is approximately equal to the summation of individual $V_{\text {oc }}$ of top and bottom cells, as expected. To maximize $V_{\text {oc }}$ of the tandem cell, individual open circuit voltages need to be maximized. In theory, $V_{\text {oc }}$ of a solar cell increases logarithmically with optical generation rate. However, recombination of electrons and holes significantly limits the increment of $V_{\mathrm{oc}}$ at higher thicknesses. It can be seen that $V_{\mathrm{oc}}$ of tandem cell remains high in the region of $\sim 140-260 \mathrm{~nm}$ CZTS

and $\sim 850 \mathrm{~nm}$ CZTSe. Beyond that particular region, $V_{\text {oc }}$ of tandem cell falls due to recombination effects and mismatch of optical power absorption between top and bottom cells.

Finally, we analyzed the variation of tandem efficiency $\left(\eta_{\text {tandem }}\right)$ with top and bottom cells' absorber thicknesses. We found that a maximum efficiency of $19.87 \%$ can be obtained for a particular combination of thicknesses $(\sim 200 \mathrm{~nm}$ CZTS and $\sim 850 \mathrm{~nm}$ CZTSe). Fig. 7(d) shows the $J-V$ characteristics of tandem cell at that particular combination while Fig. 8 shows the absorption spectrum for the same. We also calculated the efficiency of optimized tandem cell without recombination effects. That yields to a $23.94 \%$ efficient CZTS/CZTSe tandem cell with $V_{\mathrm{oc}}=1.542 \mathrm{~V}, J_{\mathrm{sc}}=19.83 \mathrm{~mA} \mathrm{~cm}^{-2}$ and $\mathrm{FF}=0.785$. Therefore, it can be inferred that low minority carrier life time significantly limits the efficiency of the CZTS/CZTSe solar cell by decreasing its open circuit voltage and fill factor significantly. It can also be noted that the proposed cell could yield $25 \%$ more efficiency ( $>20 \%$ as opposed to $16 \%$ ) than that of perovskite/ CZTSSe structure reported by Todorova et al. ${ }^{25}$

The experimentally reported tunable band gaps of CZTS and CZTSe vary in the range of 1.4-1.56 eV and, 0.9-1.12 eV (ref. 15, 35 and 36) respectively which enabled the proposed tandem configuration and thus far, we have used $1.56 \mathrm{eV}$ and $1.04 \mathrm{eV}$ as the band gap of CZTS and CZTSe, in that order. Now, we examine the dependence of tandem cell's $V_{\mathrm{oc}}, J_{\mathrm{sc}}$ and $\eta$ on the band gap of main absorbers (Fig. 9), keeping the absorber thicknesses fixed at previously optimized values. Due to heterojunction characteristics, built-in potential of top and bottom cells increases with the band gap of absorbers. ${ }^{62}$ This increment results in overall increase in the built-in potential of the tandem cell. As a result, $V_{\mathrm{oc}}$ of tandem cell is enhanced and a maximum value of $1.544 \mathrm{~V}$ was estimated (Fig. 9(a)). Moreover, the collection probability of electrons and holes in a solar cell increases with built-in potential which consequently increases its $J_{\mathrm{sc}}$. As can be seen from Fig. $9(\mathrm{~b}), J_{\mathrm{sc}}$ of tandem cell slightly increases with the band gap of CZTS and CZTSe. However, the increase in $J_{\mathrm{sc}}$ is relatively very small compared to the increase

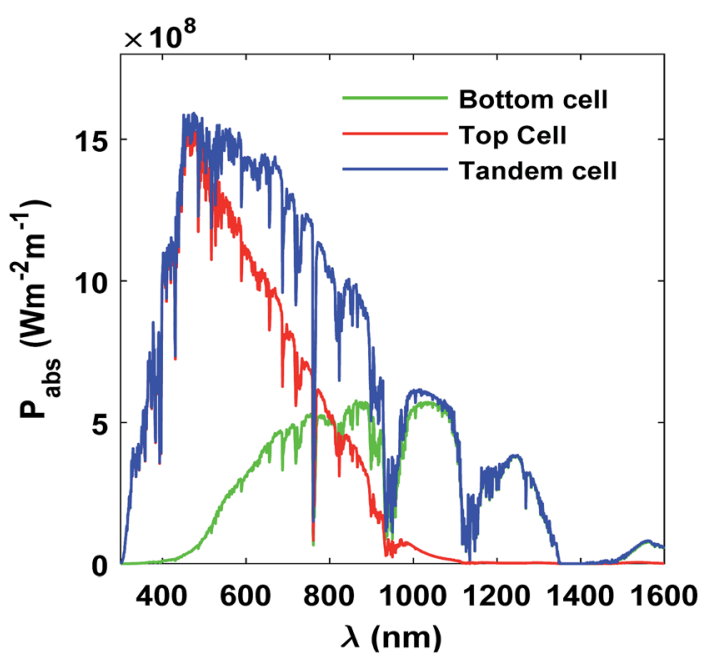

Fig. 8 Absorbed power spectrum $\left(P_{\text {abs }}\right)$ of top and bottom cells along with the absorbed power of the tandem cell at different wavelengths $(\lambda)$. 
of $V_{\text {oc }}\left(7.69 \%\left(V_{\text {oc }}\right)\right.$ as opposed to $\left.1.83 \%\left(J_{\text {sc }}\right)\right)$. Finally, Fig. 9(c) shows the variation of efficiency with the band gap of the absorbers. A maximum value of $21.74 \%$ was estimated when band gap of CZTS and CZTSe absorbers are both at their maximum values. It should be mentioned that kesterite being a fairly new field in the solar cell arena, detail and concrete material data as well as analysis are still not available for all compositions (for example, variation of optical constants with band gaps). Thus, in this band gap dependency analysis, we have used the same refractive index and extinction coefficient for all combinations, due to the absence of concrete optical data in literature for tunable kesterites. The qualitative behavior of $V_{\mathrm{oc}}, J_{\mathrm{sc}}$ and $\eta$ is similar to that of other tandem cells. ${ }^{25}$

In closing, we studied the effect of buffer layer material on the performance of our proposed cell. As cadmium (Cd) is toxic and environment pollutant, from the industrial point of view, use of CdS should be as less as possible. ${ }^{63,64} \mathrm{ZnS}$, as an alternative buffer layer, could replace CdS because of its eco-friendly nature and cheap synthesis process. ${ }^{65}$ We investigated the performance of tandem cell with ZnS buffer layer instead of CdS at the optimized condition. Following the described optimization methodology, we matched the current densities of top and bottom cells by varying absorbers thickness (top cell's $J_{\mathrm{sc}}=19.47 \mathrm{~mA} \mathrm{\textrm {cm } ^ { - 2 }}$, bottom cell's $J_{\mathrm{sc}}=19.89 \mathrm{~mA} \mathrm{~cm}^{-2}$ ). It was seen that the optimized thicknesses of CZTS and CZTSe with ZnS buffer layer had changed to $230 \mathrm{~nm}$ and $1200 \mathrm{~nm}$, respectively. The same parameters listed in the Table 3 were used in the simulation. ZnS film has a band gap of $\sim 3.58 \mathrm{eV}$ which is much higher than that of CdS $(\sim 2.42 \mathrm{eV}) .{ }^{55,57,58}$ Due to its higher band gap and lower extinction coefficient, ${ }^{66}$ most photons pass through the buffer layer without absorption, and

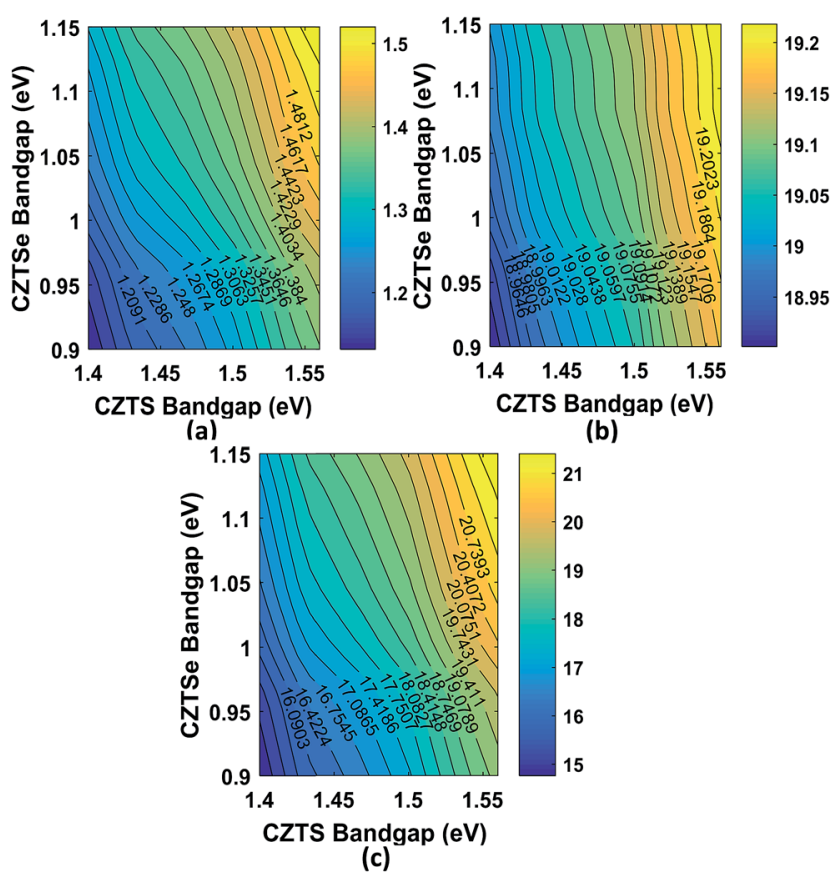

Fig. 9 Characteristics of tandem cell with the variation of bandgap of the main absorbers (a) open circuit voltage, $V_{\text {oc }}(b)$ short circuit current density $J_{\mathrm{sc}}$ and (c) Efficiency of the tandem cell, $\eta_{\text {tandem }}$ where the thickness of CZTS and CZTSe are $200 \mathrm{~nm}$ and $850 \mathrm{~nm}$, respectively.

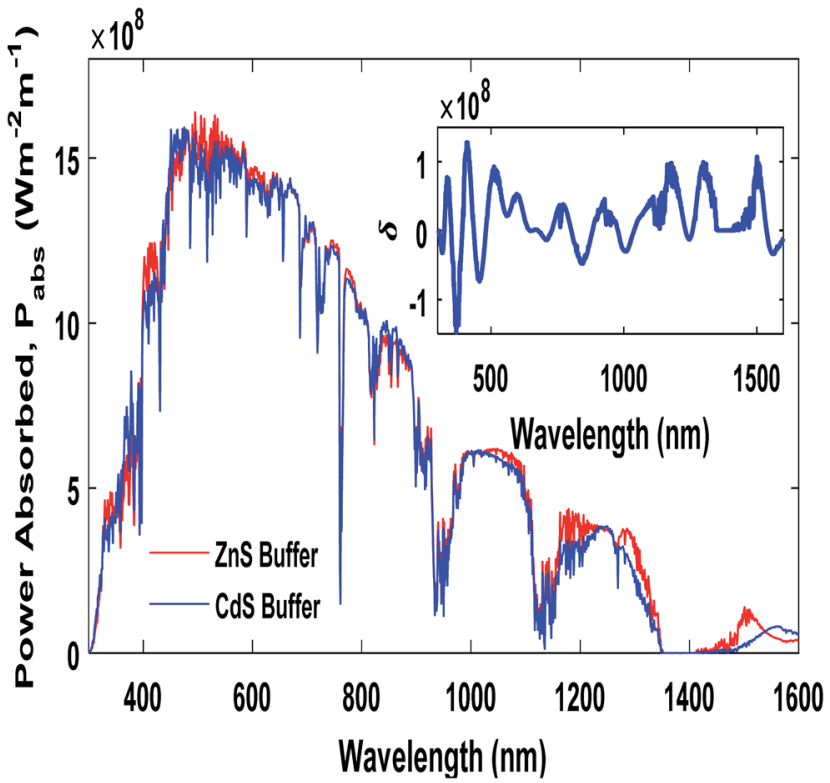

Fig. 10 Comparison of absorbed power in the tandem cell with ZnS and $\mathrm{CdS}$ buffer layers. Inset shows the difference in absorbed power for the two cases $\left[\delta=P_{\text {abs }}(\mathrm{ZnS})-P_{\mathrm{abs}}(\mathrm{CdS})\right]$

Table 4 Comparison between the optimized performance metrics of tandem cell with CdS and ZnS buffer layers

\begin{tabular}{lllll}
\hline Buffer layer & $V_{\mathrm{oc}}(\mathrm{V})$ & $J_{\mathrm{sc}}\left(\mathrm{mA} \mathrm{cm}^{-2}\right)$ & $\mathrm{FF}$ & Efficiency (\%) \\
\hline CdS & 1.431 & 19.17 & 0.726 & 19.86 \\
ZnS & 1.492 & 19.59 & 0.734 & 21.44
\end{tabular}

able to reach to the main active layers. Thus, an increment in the thicknesses of main active layers was observed at the optimum condition compared to the previous case (CdS buffer). It is also found that the main absorbers utilize the solar spectrum slightly more efficiently at some wavelengths for ZnS buffer (Fig. 10). Moreover, the higher minority carrier mobility in $\mathrm{ZnS}\left(40 \mathrm{~cm}^{2} \mathrm{~V}^{-1}\right.$ $\mathrm{s}^{-1}$ ) (CdS: $15 \mathrm{~cm}^{2} \mathrm{~V}^{-1} \mathrm{~s}^{-1}$ ) facilitates a higher collection efficiency of minority carriers. All these facts contribute to a higher $J_{\mathrm{sc}}$ when ZnS buffer layer is used. In addition, $V_{\text {oc }}$ also increases slightly due to higher optical absorption at the optimized condition. In total, $8 \%$ efficiency increment (relative) was observed when $\mathrm{ZnS}$ is used as buffer layer. Table 4 gives a comparison between the optimized performance of tandem cell with CdS and ZnS.

\section{Conclusion}

In summary, we analyzed the prospect of $\mathrm{Cu}_{2} \mathrm{ZnSnS}_{4} / \mathrm{Cu}_{2} \mathrm{ZnSnSe}_{4}$ tandem topology where both top and bottom cells have kesterite structures. CZTS and CZTSe absorbers were used to utilize the lower and higher wavelengths of solar spectrum, respectively. Thickness of the absorbers was also optimized for current matching condition of top and bottom cells and thereby best performance metrics were estimated. The maximum efficiency found from the calculation exceeds the previously proposed 
perovskite/kesterite tandem topology. In addition, the band gap analysis shows further enhancement in tandem efficiency when higher band gaps are used. Such enhancement is achievable due to the tunable property of kesterite. Finally, it was shown that replacing the CdS buffer layer with $\mathrm{ZnS}$ buffer layer leads to overall higher efficiency when the absorber layers are properly optimized. The proposed structure could make an eco-friendly, cheap allkesterite solar cell with $\eta_{\text {tandem }} \geq 20 \%$. The analysis presented in this regard would help in optimizing such tandem devices.

\section{References}

1 M. Kumar, A. Dubey, N. Adhikari, S. Venkatesan and Q. Qiao, Energy \& Environmental Science, 2015, 8, 3134-3159.

2 S. López-Marino, Y. Sánchez, M. Espíndola-Rodríguez, X. Alcobé, H. Xie, M. Neuschitzer, I. Becerril, S. Giraldo, M. Dimitrievska and M. Placidi, J. Mater. Chem. A, 2016, 4, 1895-1907.

3 J. Oh, H.-C. Yuan and H. M. Branz, Nat. Nanotechnol., 2012, 7, 743-748.

4 S. C. Riha, B. A. Parkinson and A. L. Prieto, J. Am. Chem. Soc., 2011, 133, 15272-15275.

5 A. Shah, P. Torres, R. Tscharner, N. Wyrsch and H. Keppner, science, 1999, 285, 692-698.

6 M. A. Green, K. Emery, Y. Hishikawa, W. Warta and E. D. Dunlop, Prog. Photovoltaics, 2016, 24, 905-913.

7 A. Polizzotti, I. L. Repins, R. Noufi, S.-H. Wei and D. B. Mitzi, Energy \& Environmental Science, 2013, 6, 3171-3182.

8 J. J. Scragg, P. J. Dale, L. M. Peter, G. Zoppi and I. Forbes, Phys. Status Solidi B, 2008, 245, 1772-1778.

9 X. Liu, Y. Feng, H. Cui, F. Liu, X. Hao, G. Conibeer, D. B. Mitzi and M. Green, Progress in Photovoltaics: Research and Applications, 2016, 24, 879-898.

10 S. Chen, X. Gong, A. Walsh and S.-H. Wei, Appl. Phys. Lett., 2010, 96, 021902.

11 W. Wang, M. T. Winkler, O. Gunawan, T. Gokmen, T. K. Todorov, Y. Zhu and D. B. Mitzi, Adv. Energy Mater., 2014, 4, 1301465.

12 L. Yin, G. Cheng, Y. Feng, Z. Li, C. Yang and X. Xiao, RSC Adv., 2015, 5, 40369-40374.

13 D. B. Mitzi, O. Gunawan, T. K. Todorov, K. Wang and S. Guha, Sol. Energy Mater. Sol. Cells, 2011, 95, 1421-1436.

14 W. Wang, H. Shen, L. H. Wong, Z. Su, H. Yao and Y. Li, RSC Adv., 2016, 6, 54049-54053.

15 K. Ito, Copper Zinc Tin Sulfide-Based Thin Film Solar Cells, John Wiley \& Sons, Ltd, 2015.

16 T. P. Dhakal, C. Y. Peng, R. R. Tobias, R. Dasharathy and C. R. Westgate, Sol. Energy, 2014, 100, 23-30.

17 Y.-T. Hsieh, Q. Han, C. Jiang, T.-B. Song, H. Chen, L. Meng, H. Zhou and Y. Yang, Adv. Energy Mater., 2016, 6, 1502386.

18 M. Neuschitzer, J. Marquez, S. Giraldo, M. Dimitrievska, M. Placidi, I. Forbes, V. Izquierdo-Roca, A. Pérez-Rodriguez and E. Saucedo, J. Phys. Chem. C, 2016, 120, 9661-9670.

19 G. Y. Kim, D. H. Son, T. Thi Thu Nguyen, S. Yoon, M. Kwon, C. W. Jeon, D. H. Kim, J. K. Kang and W. Jo, Prog. Photovoltaics, 2016, 24, 292-306.
20 B. Vermang, Y. Ren, O. Donzel-Gargand, C. Frisk, J. Joel, P. Salomé, J. Borme, S. Sadewasser, C. Platzer-Björkman and M. Edoff, IEEE J. Photovolt., 2016, 6, 332-336.

21 F. Liu, C. Yan, J. Huang, K. Sun, F. Zhou, J. A. Stride, M. A. Green and X. Hao, Adv. Energy Mater., 2016, 6, 1600706. 22 Y. Zhang, M. Ito, T. Tamura and A. Yamada, Appl. Phys. Express, 2011, 4, 052301.

23 K. Sun, C. Yan, F. Liu, J. Huang, F. Zhou, J. A. Stride, M. Green and X. Hao, Adv. Energy Mater., 2016, 6, 1600046.

24 C. Yan, F. Liu, K. Sun, N. Song, J. A. Stride, F. Zhou, X. Hao and M. Green, Sol. Energy Mater. Sol. Cells, 2016, 144, 700706.

25 T. Todorov, T. Gershon, O. Gunawan, C. Sturdevant and S. Guha, Appl. Phys. Lett., 2014, 105, 173902.

26 G. Niu, X. Guo and L. Wang, J. Mater. Chem. A, 2015, 3, 89708980.

27 M. Batmunkh, C. J. Shearer, M. J. Biggs and J. G. Shapter, J. Mater. Chem. A, 2015, 3, 9020-9031.

28 S. Ma, H. Zhang, N. Zhao, Y. Cheng, M. Wang, Y. Shen and G. Tu, J. Mater. Chem. A, 2015, 3, 12139-12144.

29 A. Babayigit, D. D. Thanh, A. Ethirajan, J. Manca, M. Muller, H.-G. Boyen and B. Conings, Sci. Rep., 2016, 6, 18721.

30 F. Shao, L. Xu, Z. Tian, Y. Xie, Y. Wang, P. Sheng, D. Wang and F. Huang, RSC Adv., 2016, 6, 42377-42381.

31 H. Azimi, Y. Hou and C. J. Brabec, Energy \& Environmental Science, 2014, 7, 1829-1849.

32 Z. Li, J. C. Ho, K. K. Lee, X. Zeng, T. Zhang, L. H. Wong and Y. M. Lam, RSC Adv., 2014, 4, 26888-26894.

33 X. Lin, J. Kavalakkatt, M. C. Lux-Steiner and A. Ennaoui, Adv. Sci., 2015, 2, 1500028.

34 J. Tao, K. Zhang, C. Zhang, L. Chen, H. Cao, J. Liu, J. Jiang, L. Sun, P. Yang and J. Chu, Chem. Commun., 2015, 51, 10337-10340.

35 S.-Y. Kuo and M.-Y. Hsieh, Nanoscale, 2014, 6, 7553-7559.

36 S. Bag, O. Gunawan, T. Gokmen, Y. Zhu, T. K. Todorov and D. B. Mitzi, Energy \& Environmental Science, 2012, 5, 70607065.

37 B. Shin, O. Gunawan, Y. Zhu, N. A. Bojarczuk, S. J. Chey and S. Guha, Prog. Photovoltaics, 2013, 21, 72-76.

38 J. Ge, J. Chu, J. Jiang, Y. Yan and P. Yang, ACS Appl. Mater. Interfaces, 2014, 6, 21118-21130.

39 C.-C. Liu, Y.-C. Liang, C.-C. Kuo, Y.-Y. Liou, J.-W. Chen and C.-C. Lin, Sol. Energy Mater. Sol. Cells, 2009, 93, 267-272.

40 H. Liu, Y. Tian, Y. Zhang, K. Gao, K. Lu, R. Wu, D. Qin, H. Wu, Z. Peng, L. Hou and W. Huang, J. Mater. Chem. C, 2015, 3, 4227-4234.

41 H. Muguerra, G. Berthoux, W. Z. N. Yahya, Y. Kervella, V. Ivanova, J. Boucle and R. Demadrille, Phys. Chem. Chem. Phys., 2014, 16, 7472-7480.

42 M. Bass, C. DeCusatis, J. Enoch, V. Lakshminarayanan, G. Li, C. Macdonald, V. Mahajan and E. Van Stryland, Handbook of optics, Volume II: Design, fabrication and testing, sources and detectors, radiometry and photometry, McGraw-Hill, Inc., 2009.

43 W. Bond, J. Appl. Phys., 1965, 36, 1674-1677.

44 M. Debenham, Appl. Opt., 1984, 23, 2238-2239. 
45 M. Fang, A. Aristov, K. V. Rao, A. V. Kabashin and L. Belova, RSC Adv., 2013, 3, 19501-19507.

46 C. A. Klein, Appl. Opt., 1986, 25, 1873-1875.

47 H. Li, J. Phys. Chem. Ref. Data, 1980, 9, 161-290.

48 E. D. Palik, Handbook of optical constants of solids, Academic press, 1998.

49 R. Treharne, A. Seymour-Pierce, K. Durose, K. Hutchings, S. Roncallo and D. Lane, 2011.

50 J.-H. Lee, K.-H. Ko and B.-O. Park, J. Cryst. Growth, 2003, 247, 119-125.

51 S. Bag, O. Gunawan, T. Gokmen, Y. Zhu and D. B. Mitzi, Chem. Mater., 2012, 24, 4588-4593.

52 V. P. Devarajan, D. Nataraj, T. Pazhanivel, K. Senthil, M. Seol, K. Yong, J. Hermannsdorfer and R. Kempe, J. Mater. Chem., 2012, 22, 18454-18462.

53 Z. Fan and J. G. Lu, J. Nanosci. Nanotechnol., 2005, 5, 15611573.

54 A. Janotti and C. G. Van de Walle, Rep. Prog. Phys., 2009, 72, 126501.

55 A. Jha, S. K. Sarkar, D. Sen and K. Chattopadhyay, Nanoscale, 2015, 7, 2536-2544.

56 S.-Y. Kuo and M.-Y. Hsieh, Nanoscale, 2014, 6, 7553-7559.
57 J. Leitao, N. M. Santos, P. Fernandes, P. Salome, A. da Cunha, J. González, G. Ribeiro and F. Matinaga, Phys. Rev. B: Condens. Matter Mater. Phys., 2011, 84, 024120.

58 O. Madelung, Semiconductors: data handbook, Springer Science \& Business Media, 2012.

59 W. Martienssen and H. Warlimont, Springer handbook of condensed matter and materials data, Springer Science \& Business Media, 2006.

60 D. P. Norton, Y. Heo, M. Ivill, K. Ip, S. Pearton, M. F. Chisholm and T. Steiner, Mater. Today, 2004, 7, 34-40.

61 G. Paul, S. Bandyopadhyay and S. Sen, Phys. Status Solidi A, 2002, 191, 509-518.

62 D. A. Neamen, Semiconductor Physics and Devices: Basic Principles, McGraw-Hill Education, 2012.

63 A. Bernard, Indian J. Med. Res., 2008, 128, 557.

64 S. T. Hossain and S. K. Mukherjee, J. Hazard. Mater., 2013, 260, 1073-1082.

65 T.-H. Yeh, C.-H. Hsu, W.-H. Ho, S.-Y. Wei, C.-H. Cai and C.-H. Lai, Green Chem., 2016, 18, 5212-5218.

66 A. Goudarzi, A. D. Namghi and C.-S. Ha, RSC Adv., 2014, 4, 59764-59771. 